\title{
LA MISIÓN DE LOS DISCÍPULOS DE JESÚS
}

Autor: Santiago Guijarro. Sacerdote Operario Diocesano. Profesor de Nuevo Testamento en la Universidad Pontificia de Salamanca (España). Vicerrector de la misma Universidad.

El envío de los discípulos aparece en los evangelios como el último eslabón de un proceso que comenzó en el mismo momento en que Jesús los llamó para que le siguieran: "Veníos detrás de mí y os haré pescadores de hombres" (Mc 1,17); o cuando les reunió en torno a sí para formar el grupo de los Doce: "Los llamó para que estuvieran con él y para enviarlos a predicar" (Mc 3,14)1. El siguiente paso en este proceso fue la experiencia, más dilatada en el tiempo, del discipulado. Esta experiencia fue un requisito imprescindible para la tarea misionera, y por eso Jesús envió sólo a quienes antes habían formado parte del grupo de sus discípulos más cercanos, es decir, a aquellos que habían

${ }^{1}$ La misión es un elemento constitutivo de la llamada, aunque este dato aparece con más claridad en los relatos de Marcos, que en los de Q o Juan. Véase: S. Guijarro Oporto, "Vocación" en: F. Fernández Ramos (dir.), Diccionario de Jesús de Nazaret (Burgos: Ed. Monte Carmelo 2001) 1303-1314; pp. 1304 y 1313 
escuchado sus enseñanzas y habían sido testigos de sus signos; los que habían compartido su estilo de vida y su destino (Mc 6,7)2.

Fiel al proverbio rabínico, según el cual "el enviado de un hombre es como si fuera él mismo", Jesús llamó e instruyó a sus discípulos para que fueran sus enviados en este sentido integral, es decir, para que realizaran signos que confirmaran lo que anunciaban, y vivieran de acuerdo con el mensaje que proclamaban ${ }^{3}$. Esto significa que la vocación y el discipulado tienen como meta la misión, y que están determinados por ella. Significa también, que lo específico de la llamada de Jesús y de la experiencia discipular a que dio origen se explica, en gran medida, por la naturaleza propia de la misión que quiso encomendar a sus discípulos.

No es extraño, por tanto, que la crisis vocacional que estamos viviendo nos haya llevado a reflexionar sobre la misión ${ }^{4}$. En las experiencias vocacionales recogidas en la Biblia la llamada está siempre en función de una misión. Dios llama para encomendar una tarea al servicio de su plan de salvación, y esta tarea configura y determina, en gran medida, la llamada.

Este es el marco del presente estudio sobre la misión de los discípulos en los evangelios. Volvemos nuestra mirada hacia aquella primera experiencia en la que vocación, discipulado y misión formaban parte de un mismo proceso, y la contemplamos desde la perspectiva de la misión. El punto de partida serán los textos evangélicos que hablan más explícitamente sobre la misión de los discípulos. Comenzaremos señalando los acentos propios de cada evangelio. Después trataremos de identificar cuáles de estas tradiciones proceden de Jesús. Y finalmente nos preguntaremos cuál fue la intención de Jesús al enviar a sus discípulos y cómo entendía él la misión que les encomendó.

2 Sobre las características propias del discipulado de Jesús, véase: S. Guijarro Oporto, "Discipulado", en F. Fernández Ramos (dir.), Diccionario de Jesús de Nazaret... 276285, pp. 282-285.

${ }^{3}$ Sobre la institución del shaliaj (enviado) en el Judaísmo, puede verse: K. H. Rengstorf, "apostellô ktl" en G. Kittel (ed.), Theological Dictionary of the New Testament (Grand Rapids Mi.: Eerdmans 1964) I, 398-447, pp. 413-420.

${ }^{4}$ No es casual que el título del último Plan Pastoral de los obispos españoles se inspire en una palabra de Jesús con claras connotaciones misioneras: "Mar adentro" (Lc 5,4), Vida Nueva 2317 (16 Feb 2002) 23-30; 2318 (23 Feb 2002) 23-29. 


\section{El envío de los discípulos en los evangelios}

El envío de los discípulos, tal como aparece actualmente en los evangelios, refleja en parte las preocupaciones de las comunidades para las que se escribieron, pero al mismo tiempo conserva una antiquísima tradición que se remonta a Jesús. En este primer paso de nuestro acercamiento, tratamos de hacer un elenco de los pasajes relacionados con la misión. No pretendemos hacer un estudio en profundidad de cómo entendían los evangelistas y sus comunidades la misión, sino acotar los textos que nos darán acceso a la experiencia del primer envío misionero de los discípulos.

\section{El envío de los discípulos en el evangelio de Marcos}

En el evangelio de Marcos, que es el más antiguo de los cuatro, no encontramos ninguna tradición referida al envío de los discípulos después de Pascua. Como es sabido, este evangelio terminaba originalmente en Mc 16,8, sin narrar ninguna aparición del resucitado a los discípulos. El llamado final largo (Mc 16,9-20) sí contiene un encuentro en el que Jesús confía a sus discípulos una misión (Mc 16,14-18), pero este final fue añadido al evangelio en época muy tardía.

El texto más importante sobre el envío de los discípulos durante el ministerio de Jesús es el llamado encargo misionero (Mc 6,7-13. 30 $31)^{5}$. En él se cuenta cómo Jesús llamó a los Doce para enviarlos de dos en dos con poder para realizar curaciones y exorcismos, y cómo éstos regresaron para comunicarle el resultado de su misión. En el envío inicial se recogen una serie de instrucciones sobre la forma de realizar esta misión. Sólo de pasada se dice que su anuncio tiene que ver con la paz y con la conversión, pero el centro de la misión no parece ser este anuncio, sino los signos que llevan la marca de Jesús, y el comportamiento de los misioneros.

Dentro del evangelio de Marcos, este pasaje está estrechamente relacionado con otros dos: la llamada a los cuatro primeros discípulos (Mc 1,16-20) y la constitución del grupo de los Doce (Mc 3,13-19). En

5 Véase: J. Gnilka, El Evangelio según Marcos. Mc 1,1-8,26 (Salamanca: Sígueme 1986) pp. 275-283. 
estos tres pasajes se da un progreso con respecto a la misión. Desde el principio los discípulos saben que Jesús los llama para convertirlos en "pescadores de hombres" (Mc 1,17). Más adelante, el evangelista nos recuerda que Jesús constituyó el grupo de los Doce, "para que estuvieran con él", y "para enviarlos a predicar" (Mc 3,14). Esto significa que, en la visión de Marcos, la vocación está en función de la misión, aunque para llevarla a cabo los discípulos deben haber acompañado antes a Jesús, asumiendo su estilo de vida, escuchando sus enseñanzas y viendo los signos que realizaba.

Cada uno de estos tres pasajes sobre los discípulos se encuentra al comienzo de una de las tres secciones que articulan la primera parte del evangelio (Mc 1,14-3,6; 3,7-6,6a; 6,6b-8,26). A lo largo de estas tres secciones los discípulos se van identificando cada vez más con Jesús, y siguen un proceso que culmina con la confesión de Pedro (Mc 8,27-30). El último estadio de este proceso es su incorporación a la misión de Jesús. Esto significa que para Marcos todo lo que ocurre en la tercera sección $($ Mc 6,6b-8,26) tiene que ver con la misión de los discípulos. En ella aparece constantemente el tema del pan y la comida, que evocan los problemas de comunión de mesa entre judíos y paganos. En estos capítulos encontramos dos multiplicaciones de los panes: la primera está destinada a los judíos, y la segunda a los paganos. $Y$ entre ambas un proceso, una instrucción catequética dirigida a los discípulos, para que acepten en su seno a los paganos. En esta sección, por tanto, el envío misionero de Jesús arroja luz sobre una situación comunitaria. Se ha pasado del ámbito de la misión al de la organización comunitaria 6 .

Finalmente, hemos de considerar otro pasaje, que a primera vista resulta muy enigmático, pues habla de un personaje que no pertenece al grupo de los Doce, y sin embargo expulsa demonios en nombre de Jesús (Mc 9,38-41). Los discípulos van a contarle a Jesús lo que está haciendo para que se lo impida, pero él se resiste a hacerlo. En el contexto de Marcos, esta actitud de Jesús podría indicar que la misión no es patrimonio de los Doce.

${ }^{6}$ Sobre esta sección de Marcos y sus acentos eclesiológicos, puede verse: X. Pikaza, Pan, casa, palabra. La iglesia en Marcos (Salamanca: Sígueme 1998) 143-211. 
En la perspectiva de Marcos, por tanto, la misión es una realidad histórica pasada. El envío misionero de los discípulos se evoca, sobre todo, para iluminar una situación comunitaria, y para subrayar la incomprensión de los Doce, que se acrecienta a medida que avanza el relato.

\section{El envío de los discípulos en el evangelio de Mateo}

Mateo ha incorporado en su evangelio las instrucciones de Marcos sobre el envío de los discípulos, pero las ha combinado con un pasaje muy similar procedente de Q. Además, ha incorporado otros dichos de Jesús procedentes de tradiciones propias. Con todos estos materiales ha compuesto uno de los cinco grandes discursos que jalonan su evangelio (Mt 9,36-11,1). Este discurso relaciona estrechamente la constitución del grupo de los Doce con la misión a Israel. Además de este discurso misionero, el evangelio de Mateo narra una aparición del resucitado, en la que éste confía a sus discípulos una misión de tintes más universalistas (Mt 28,16-20).

El discurso misionero de Mateo es un texto complejo. En él encontramos magistralmente combinadas tradiciones procedentes de todas sus fuentes, algunas de las cuales no tenían que ver originalmente con el envío de los discípulos, sino con su estilo de vida y con las exigencias del discipulado (Mt 10,17-22.26-33.34-39). Para entender este discurso es importante tener en cuenta que en el primer evangelio la perspectiva anterior y posterior a la pascua se funden con frecuencia. Debido a ello, en este discurso encontramos unidos el primer encargo misionero de Jesús y la primera experiencia misionera de sus discípulos después de la Pascua. En el caso de Mateo, esta misión se dirigió al principio exclusivamente al pueblo de Israel (Mt 10,5b-23), y tuvo como resultado una situación dolorosa para su comunidad: persecución, delaciones, miedo y duras rupturas familiares. Esta es la situación que aparece reflejada en este discurso, sobre todo en la última parte del mismo que describe las consecuencias de dicha misión (Mt 10,24-42)7.

${ }^{7}$ Esta forma de entender el discurso misionero de Mateo depende en parte de los análisis de U. Luz, El evangelio según san Mateo. Mt 8-17 (Salamanca: Sígueme 2001) pp. 111-221, espec. pp. 113-115. Una división diferente puede verse en: W. D. Davies - D. C. Allison, The Gospel according to Matthew. Vol II (Edimburg: T \& T Clark 1989) pp. 143233, espec. pp. 161-162. 
La perspectiva del encargo misionero confiado por el resucitado a sus discípulos (Mt 28,18-20) es muy diferente a la que encontramos en el discurso misionero. La misión no va dirigida ya a "Israel" o "la casa de Israel" (Mt 10,5-6. 23), sino a "todos los pueblos" (Mt 28,19). La misión no consiste ahora en "anunciar, curar, expulsar demonios..." (Mt 10,7-8), sino en "hacer discípulos, enseñar y bautizar" (Mt 28,1920). Estas diferencias tan notables indican que estos dos pasajes se refieren a dos momentos distintos de la misión. Mateo conoce una primera misión a Israel, que tuvo como resultado el rechazo y la persecución. La versión mateana de la parábola de los viñadores malvados refleja bien este rechazo y sus consecuencias (Mt 21,33-44). Después de este rechazo, la misión se dirigió también a los no-judíos, que escucharon de buena gana el anuncio y reconocieron a Jesús como Hijo de Dios. Esta misión a todos los pueblos es la que la comunidad está llevando a cabo en la época del evangelista.

\section{El envío de los discípulos en el evangelio de Lucas}

Los pasajes del evangelio de Lucas sobre el envío de los discípulos proceden, como en el caso de Mateo, de sus fuentes (Mc y Q). Sin embargo, Lucas los ha dispuesto en su relato de una forma distinta, que refleja su propia perspectiva sobre la misión. En Lucas no encontramos fusionadas las recomendaciones sobre la misión procedentes de Mar$\cos$ y de $\mathrm{Q}$, sino que ambos pasajes se encuentran en momentos distintos del relato (Lc 9,1-6; 10,1-24). Además de estos dos pasajes referidos al envío prepascual, encontramos otro encargo misionero del Resucitado que anticipa el mandato explícito de Hechos (Lc 24,46-48 $=$ Hch 1,8$)$.

Resulta muy llamativo que este evangelio contenga dos envíos misioneros de Jesús durante su ministerio. Este hecho podría explicarse por el gran respeto de su autor hacia las fuentes que utiliza, y su reticencia a mezclarlas. Sin embargo, es posible que también le hayan guiado otras motivaciones. En el primero de estos pasajes Jesús envía a los Doce (Lc 9,1), mientras que en el segundo los enviados son "otros Setenta [y dos]" (Lc 10,1). Esta última identificación de los enviados es obra de Lucas, que ha encontrado en sus fuentes estas dos versiones del envío misionero y, en lugar de fundirlas, las ha aprovechado para rela- 
tivizar el monopolio de los Doce sobre la misión8. Jesús -viene a decir Lucas- no sólo encargó esta tarea a los Doce, sino también a otros.

Es importante advertir que el segundo envío misionero se encuentra en la sección del viaje (Lc 9,51-19,28), que es la más elaborada de todo el evangelio, y aquella en que Lucas ha dejado un sello más personal. Forma parte de un conjunto de instrucciones sobre el seguimiento y la misión, que proceden básicamente de Q (Lc 9,57-10,24). Estas enseñanzas se encuentran al comienzo del viaje, en el que Jesús instruye constantemente a sus discípulos. En el contexto de este viaje, que prefigura el paso del evangelio a los paganos, el envío de los Setenta y dos prefigura también la tarea de los misioneros helenistas, que llevaron a cabo la evangelización de Antioquía; y la de Pablo y sus colaboradores, que llevaron el evangelio a las comunidades a las que se dirige la obra de Lucas9.

Finalmente, también en Lucas encontramos un encargo misionero del Resucitado (Lc 24,44-48). El contexto es muy distinto al de Mateo, pues en Lucas esta es la tercera aparición a los discípulos (a los de Emaús, a Pedro, y ahora a todos los discípulos). Sin embargo, a pesar de las diferencias externas, el contenido es bastante parecido. Se trata de una misión "a todos los pueblos" para la que Jesús les anuncia que enviará "el don prometido por el Padre", es decir el Espíritu. Este mismo encargo misionero aparece al comienzo del libro de los Hechos de forma más explícita (Hch 1,8). Los dos rasgos propios de esta misión, que se irá desplegando a lo largo del libro, son la asistencia del Espíritu y la caracterización de los misioneros como testigos. Se trata de una misión que muy bien podría entenderse como una continuación de la emprendida por los setenta y dos en vida de Jesús.

En la perspectiva de Lucas, por tanto, la misión es también un acontecimiento del pasado. Hubo una primer envío de los Doce a Israel, y luego un segundo envío que traspasó las fronteras de Judaísmo. Gracias a él surgieron las comunidades a las que ahora se dirige el

${ }^{8}$ R. Tannehill, The Narrative Unity of Luke-Acts. A Literary Interpretation. Volume One: Teh Gospel according to Luke (Philadelphia: Fortress Press 1986) pp. 232-237. Véase también: J. Fitzmyer, El evangelio según san Lucas. Vol III (Madrid: Ed. Cristiandad 1987) pp. 53-60 y 202-218.

${ }^{9}$ M. Laconi, San Lucas y su iglesia (Estella: Verbo Divino 1986) pp. 65-68; sobre el sentido del viaje, pueden verse también, pp. 69-83. 
evangelio. En los textos lucanos sobre la misión no hay indicios de que sus comunidades estén llevando a cabo una actividad misionera como la de Jesús o los cristianos de la primera generación.

\section{El envío de los discípulos en el evangelio de Juan}

En el evangelio de Juan se habla mucho de la misión de Jesús, a quien se describe con frecuencia como el enviado del Padre (Jn 3,1619). Sin embargo, no encontramos en este evangelio ninguna de las tradiciones sinópticas sobre el envío prepascual de los discípulos, porque el discipulado no tiene en él como objetivo prioritario la misión, sino un proceso de iniciación que culmina con la efusión del Espíritu. Por esta razón, el envío de los discípulos en este evangelio tiene lugar solamente después de la Pascua.

Este envío aparece explícitamente en dos textos, y en los dos se presenta en continuidad con la misión de Jesús. En Jn 17,18 se dice que Jesús ha enviado a sus discípulos al mundo, y podría dar la impresión de que se trata de un acontecimiento pasado. En realidad esta parte de la oración final de Jesús es un resumen de lo que ha sucedido en la comunidad joánica en la primera generación cristiana (Jn 17,9), y por tanto este envío es el mismo del que habla el otro pasaje, que recoge el mandato misionero del Resucitado (Jn 20,21). Este es el texto clave para entender lo que significa la misión en el evangelio de Juan, pues este envío forma parte de la experiencia del encuentro con el Resucitado en el que tiene lugar la efusión del Espíritu. Es el momento en que se completa la iniciación de los discípulos, uno de cuyos rasgos característicos es, precisamente, el envío misionero ${ }^{10}$. Según Juan, por tanto, la misión no es tarea de unos pocos, sino de todos aquellos discípulos que han completado su proceso de iniciación. Su misión hacia el mundo se entiende como una continuación de la de Jesús, que había sido enviado por el Padre. Para ello cuentan con la asistencia del Espíritu que será su defensor frente al mundo (Jn 16,8-11).

10 Este visión del discipulado en Juan como un proceso de iniciación ha sido propuesta recientemente de forma bastante convincente por: A. Destro,- M. Pesce, Come nasce una Religione. Antropología ed esegesi del Vangelo di Giovanni (Roma: Laterza 2000). 
Hay en Juan, finalmente, una alusión enigmática de Jesús a la misión en Samaría (Jn 4,35-38). El vocabulario que se utiliza para designar la misión (cosecha, sembrar, cosechar) evoca algunos otros dichos de los Sinópticos (Lc 10,1 par.), pero resulta poco probable que estas palabras se refieran a una misión encargada por Jesús a sus discípulos durante su ministerio. En ellas se pueden adivinar diversas fases de la evangelización de Samaría, que cuadran mejor con los datos del libro de los Hechos sobre la actividad de los misioneros cristianos en Samaría después de la Pascua (Hch 8,4-25) ${ }^{11}$.

Este repaso de los textos evangélicos que hacen referencia a la misión nos ha mostrado que no era una actividad prioritaria para las comunidades cristianas de la segunda generación. Al menos no lo era en la forma en que había sido llevada a cabo primero por Jesús y luego por los misioneros de la primera generación. Durante la segunda generación cristiana la mayor parte de las energías de las comunidades cristianas estaban concentradas en la estructuración interna de las mismas. La gran labor misionera llevada a cabo durante la primera generación, ampliamente reseñada en las cartas de Pablo y en el libro de los Hechos, había dejado paso a un proceso de consolidación interna de las comunidades nacidas de dicha misión. Para la mayoría de cristianos de la segunda generación la tarea misionera pertenecía al pasado fundacional de la Iglesia12.

A pesar de ello, tuvieron gran interés en conservar los recuerdos sobre el envío misionero de los discípulos, porque intuían que aquella primera misión sería siempre punto de referencia obligado para los seguidores de Jesús. Esa es también la convicción que nos mueve a

${ }^{11}$ Sobre la relación entre ambos pasajes puede verse el artículo clásico de O. Cullmann, "Samaría y los orígenes de la misión cristiana. ¿Quiénes son los alloi de Jn 4,35", en O. Cullmann (ed.) Del evangelio a la formación de la teología cristiana (Salamanca: Sígueme 1972) pp. 67-77.

12 En un reciente estudio sobre la misión en la Iglesia de los primeros siglos, R. Trevijano afirma rotundamente: "No consta que después de San Pablo la Iglesia primitiva haya desarrollado un esfuerzo misionero consciente, formal o institucionalizado"; R. Trevijano Etcheverría, "Factores, oportunidades e incentivos para la misión en la Iglesia prenicena" Salmanticensis 47 (2000) 393-432, p. 393. Véase también: S. Guijarro Oporto, "Cristianos en el mundo. Las comunidades cristianas de la segunda generación en la sociedad helenístico-romana" Salmanticensis 48 (2001) 5-39, pp. 26-30. 
nosotros a preguntarnos por la antigüedad y fiabilidad histórica de estas tradiciones sobre la misión.

\section{Tradiciones históricas sobre el envío de los discípulos}

Cuando nos acercamos a estas tradiciones con una preocupación histórica, lo primero que se observa es que la mayoría de ellas se encuentran en las fuentes más antiguas: Mc y Q. Este es un dato importante a favor de su valor histórico. El origen de las tradiciones sobre el envío posterior a la Pascua es menos claro, pues las divergencias entre los evangelistas inducen a pensar que su formulación depende mucho de las intenciones de cada uno de ellos. Vamos a examinar ahora estas tradiciones para averiguar cuáles de ellas pueden atribuirse a Jesús.

\section{Instrucciones para la misión}

Las instrucciones para la misión se encuentran en dos versiones independientes que, sin embargo, tienen bastantes elementos en común: Mc 6,7-13 y Lc 10,1-12 // Mt 10,5-15 (Q) ${ }^{13}$. Se trata de dos agrupaciones de dichos, que probablemente fueron pronunciados en circunstancias diversas. En ellas se habla de la situación que motiva el envío, de su finalidad, y sobre todo se dan una serie de recomendaciones sobre cómo actuar mientras se lleva a cabo dicha misión.

En la tradición de Q, la situación en que se encuentra Israel es comparable a una abundante cosecha que es necesario recoger urgentemente (Mt 9,37s; Lc 10,2). La imagen de la mies y de la cosecha se encuentra también en el único pasaje joánico que habla de la misión (Jn 4,35-38). Mateo ha unido esta imagen con otra que Marcos sitúa en el contexto de la multiplicación de los panes: la de las ovejas que no tienen pastor (Mt 9,36; Mc 6,34). Marcos utiliza, además, la imagen de

13 Sobre las instrucciones de Mc 6, véase el análisis de: J. Marcus, Mark 1-8. A New Translation with Introduction and Commentary. The Anchor Bible (New York: Doubleday 2000) pp. 382-391. Y sobre las de Q 10, el estudio clásico de: J. S. Kloppenborg, The Formation of Q. Trajectories in Ancient Wisdom Collections (Philadelphia: Fortress Press 1987) pp. 192-197; o el más reciente de: R. A. Horsley - J. A. Draper, Whoever Hears You, Hears Me. Prophets, Performance and Tradition in $Q$ (Harrisburg, Pnna.: Trinity Press 1999) pp. 228-249. 
la pesca, cuando promete a sus primeros discípulos que los convertirá en "pescadores de hombres" (Mc 1,17). Todas estas imágenes, a pesar de su diversidad, reflejan una misma forma de entender la misión. La cosecha y la pesca tienen claras connotaciones escatológicas, lo mismo que la promesa de un pastor que convocará finalmente a Israel. Lo más probable es que esta forma de entender la misión se remonte a Jesús.

En las instrucciones sobre la misión se hace referencia también a la finalidad de la misma. Según la versión de Marcos, Jesús envió a sus discípulos con poder para expulsar demonios (Mc 6,7), aunque el evangelista aclara al final que "predicaron para que se convirtieran, y expulsaban muchos demonios, y ungían con aceite a muchos enfermos y se curaban" (Mc 6,12-13). En la tradición de Q esta finalidad aparece de forma más explícita, pues, junto al mandato de curar enfermos y expulsar demonios, Jesús encomienda a sus discípulos que anuncien la inminente llegada del Reinado de Dios (Lc 10,9; Mt 10,7). A pesar de las diferencias, ambas tradiciones revelan que la misión encomendada por Jesús a sus discípulos incluía el anuncio y los signos, principalmente curaciones y exorcismos; esto indica que Jesús la entendió como una continuación de su propia misión.

Con todo, la mayor parte de los dichos contenidos en el envío misionero de Mc y Q son instrucciones sobre aspectos aparentemente secundarios: qué es lo que hay que llevar para el camino, o cómo comportarse cuando sean bien recibidos o rechazados (Mc 6,8-11 par.; Lc 10,4-12 par.). Aunque hay algunas diferencias en los detalles, llama poderosamente la atención la coincidencia en este tipo de instrucciones. Estas coincidencias revelan que ambas fuentes podrían remontarse a una misma tradición, y con mucha probabilidad a Jesús. Además, el lugar que ocupan en el conjunto de las palabras sobre el envío indica que la forma de llevar a cabo la misión no era para él separable del mensaje, de modo que estas instrucciones pueden revelarnos también aspectos importantes sobre cómo entendía Jesús la misión que encomendó a sus discípulos ${ }^{14}$.

14 Este tipo de recomendaciones son muy parecidas a las que encontramos en los filósofos cínicos de aquella época, lo cual no implica necesariamente, como algunos han sostenido recientemente, que Jesús fuera un maestro de sabiduría al estilo de estos filósofos. Un análisis bastante completo de estas semejanzas puede verse en: L. Vaage, Galilean Upstars (Valley Forge: Trinity Press International 1994) 17-39. 


\section{El regreso de los enviados}

Además de las recomendaciones sobre la misión, en los evangelios encontramos otros pasajes que se refieren a la acogida de los apóstoles enviados por Jesús. Recogemos aquí tres grupos de tradiciones: las que hablan sobre el regreso de los mensajeros, las que se refieren a la acogida de los mismos, y otras que presuponen la existencia de otros misioneros que no pertenecían al grupo de los Doce.

Del regreso de los mensajeros enviados por Jesús tenemos dos versiones. Una se encuentra en Mc 6,30s (par. Lc 9,10) y otra en Lc 10,17-20. Podemos presuponer que el texto de Lucas representa la versión de Q, aunque no tenga paralelo en Mateo. Mateo no parece estar interesado en este episodio, pues tampoco ha recogido el pasaje paralelo de Marcos. La versión de Marcos es más genérica "le contaron a Jesús todo lo que habían hecho y lo que habían enseñado", mientas que la de Q está centrada en la victoria de los discípulos sobre los demonios. Los exorcismos fueron un elemento central en la actividad de Jesús y de sus discípulos, que veían en la victoria sobre Satanás un signo evidente de que estaba alboreando el Reinado de Dios (Lc 11,1920 par. $)^{15}$. Esta versión está, pues, en consonancia con el envío de los discípulos para anunciar la llegada de dicho Reinado, y puede considerarse como una tradición prepascual.

En el evangelio de Mateo encontramos una agrupación de dichos sobre la acogida de los mensajeros (Mt 10,40-42). El primero de ellos se encuentra de formas diversas en tres fuentes independientes: Marcos (Mc 9,37); Q (Lc 10,16 par.) y Juan (Jn 5,23; 13,20). Las versiones de $\mathrm{Q}$ y de Jn 13,20 , que son muy parecidas, remiten probablemente a un dicho de Jesús, en el que resuena de nuevo la institución judía del shaliaj o enviado: quien acoge a los discípulos está acogiendo a Jesús, y a aquel que le ha enviado a él (el Padre) ${ }^{16}$. Sin embargo, los dos dichos sobre la acogida de los profetas y los justos (Mt 10,41) tienen el sello característico de Mateo, pues se trata de dos categorías de personas que en su comunidad tenían cierta importancia, y por ello

15 Sobre la importancia de los exorcimos en el envío misionero, véase: G. H. Twelftree, Jesus, the Exorcist. A Contribution to the Study of the Historical Jesus (Peabody, Ma.: Hendrickson 1993) pp. 122-127.

16 Sobre el shaliaj véase más arriba, nota 4. 
hemos de pensar que han sido compuestos por él para concretar el dicho precedente. El último dicho (Mt 10,42) procede de Mc 9,41, pero no es clara su relación con el envío misionero. En conclusión, podemos retener Mt 10,40 y par. como el único de estos dichos referidos a la misión que proceden de Jesús.

Entre las tradiciones relacionadas con la misión podemos incluir también tres dichos que hablan de personas que no pertenecen al grupo de los Doce. Ya hemos visto más arriba que la mención de los Setenta y dos en Lucas es redaccional (Lc 10,1), y que la tradición sobre los primeros misioneros de Samaría refleja una situación posterior a la Pascua (Jn 4,35-38). Nos queda la tradición sobre el "exorcista independiente" de Marcos (Mc 9,39-41), cuyo origen prepascual es bastante dudoso ${ }^{17}$. En consecuencia, estas tradiciones sobre una misión diferente a la llevada a cabo por los Doce es muy difícil que procedan de Jesús.

\section{El encargo misionero del Resucitado}

Las tradiciones sobre el envío de los discípulos después de la Pascua se diferencian notablemente de las estudiadas hasta ahora, sobre todo porque no se encuentran en las fuentes más antiguas (Mc y Q), sino en los evangelios más tardíos (Mt 28,18-20; Lc 24,46-48 // Hch 1,8 ; y Jn 17,18; 20,21.). Todos estos pasajes se encuentran en el contexto de las apariciones del Resucitado, en las que resulta fácil descubrir los intereses de sus respectivos redactores ${ }^{18}$. Estos dos datos invitan a ser cautos a la hora de valorar la antigüedad de estas tradiciones. Sin embargo, y a pesar de estas cautelas, es preciso reconocer que las palabras sobre el envío misionero tienen un carácter peculiar, y que existen entre ellas notables semejanzas.

Un dato común a todas ellas es que el envío aparece siempre en labios de Jesús. Los tres evangelistas pretenden transmitir palabras del

17 Como señala acertadamente J. Gnilka, El Evangelio según Marcos. Vol II: Mc 8,2716,20 (Salamanca: Sígueme 1986) pp. 67-72, la problemática y la formulación de este apotegma responden a preocupaciones misioneras propias de la primera generación cristiana.

18 Aunque su postura con respecto a la historicidad de los acontecimientos pascuales suscitó bastante polémica, es interesante el análisis redaccional que realiza G. Lüdemann, Die Auferstehung Jesu. Historie, Erfahrung, Theologie (Göttingen: Vandenhoeck und Ruprecht 1994) pp. 141-208. 
Resucitado. En segundo lugar, los tres mandatos misioneros tienen su fundamento en una manifestación de la gloria y el poder de Jesús. En tercer lugar, esta nueva misión tiene un destino universal, pues se dirige a los gentiles (Mt y Lc) o al mundo (Jn 17,18). Finalmente, en los tres casos se promete un apoyo a los discípulos, sea por la presencia del Espíritu (Lc y Jn), o del mismo Jesús (Mt).

Estas semejanzas podrían explicarse diciendo que los tres evangelistas están siguiendo el mismo esquema literario, pero esto no explicaría las coincidencias de contenido. En cualquier caso resulta muy difícil determinar con precisión la antigüedad de esta tradición. Sabemos que las apariciones del Resucitado fueron desde muy antiguo un elemento importante en la legitimación de los misioneros. San Pablo recurre a ella cuando su condición de apóstol es puesta en duda (1Cor 15,1-11) ${ }^{19}$. Podemos decir, por tanto, que la formulación de los envíos misioneros de los relatos de apariciones es tardía, aunque la relación entre apariciones y misión es muy antigua, y por tanto es probable que estos relatos recojan una tradición que se remonta a momento de la experiencia pascual ${ }^{20}$.

\section{Sentido y alcance del envío de los discípulos}

Los análisis precedentes nos permiten afirmar que Jesús encomendó a sus discípulos durante su ministerio público la tarea de difundir con signos y palabras el mensaje que él anunciaba. La naturaleza de esta misión explicaría las exigencias tan radicales de su llamada y seguimiento. Los discípulos debían renunciar a ciertas ataduras y obligaciones para poder dedicarse enteramente, como Jesús lo hacía, a esta tarea. La antigüedad y coherencia de los dichos relacionados con el encargo misionero avalan esta afirmación.

Para comprender adecuadamente el sentido y el alcance de la misión encomendada por Jesús a sus discípulos hemos de distinguir, como venimos haciendo, entre la misión prepascual y la pospascual. La primera es la que tiene en los evangelios una presencia mayor, y

19 Véase: F. Vouga, Los primeros pasos del Cristianismo (Estella: Verbo Divino 2001) pp. 34-39.

${ }^{20}$ Rengstorf, "apostellô... pp. 430-435. 
también la que está atestiguada en las fuentes más antiguas. En ella centramos ahora nuestra atención, con el objeto de aclarar tres cuestiones básicas: cómo entendió Jesús esta misión; qué es lo que encargó a sus discípulos; y qué es lo que nos dicen acerca de esta misión las instrucciones puntuales sobre el camino, o la acogida y el rechazo de los mensajeros.

\section{Cómo entendió Jesús la misión encomendada a sus discípulos}

La idea que Jesús tenía de la misión encomendada a los discípulos sólo nos es accesible a través de referencias indirectas. Aquí vamos a considerar tres de ellas: los términos con que designó a los enviados, las imágenes con las que describió la misión, y los destinatarios de dicha misión.

Los términos que Jesús utilizó para referirse a sus enviados no proceden de los oficios religiosos o civiles de la época, sino de oficios comunes. Los discípulos son llamados para ser pescadores, jornaleros o pastores. Algunos de estos oficios tenían, incluso, connotaciones negativas en la cultura de Jesús. Los jornaleros, por ejemplo, pertenecían al estrato más bajo de los campesinos; no tenían tierras y tenían que ofrecer su trabajo como temporeros a los propietarios del latifundio (Mt 20,1-16)21. Es muy significativo que dos de estos términos (pescadores y jornaleros) dejaran de usarse en las comunidades cristianas de la primera y segunda generación, y que el término pastor pasara a designar un oficio estable dentro de las comunidades, y no un ministerio itinerante (Hch 20,28; Ef 4,11; 1Pe 5,1-4) ${ }^{22}$. Si los evangelios han conservado esta forma de designar a los misioneros, no ha sido para justificar un uso posterior, sino porque fue así como Jesús los llamó. Este primer dato indica que Jesús no concibió la misión de sus discípulos como un quehacer organizado y estable, sino en términos de un trabajo temporal, que se realiza al servicio de otro.

Esta misma provisionalidad aparece en las imágenes que describen la misión en los dichos de Jesús. Se trata, como hemos visto ya, de

${ }^{21}$ R. Heiligenthal, "ergazomai", en: H. Balz - G. Schneider (ed.), Diccionario Exegético del Nuevo Testamento (Salamanca: Sígueme 1996) I,1567-1570, col. 1569.

22 H. Goldstein, "poimen", en: H. Balz - G. Schneider (ed.), Diccionario Exegético del Nuevo Testamento (Salamanca: Sígueme 1996) II,1050-1054, col. 1053-4. 
imágenes con intensas connotaciones escatológicas. La imagen de la siega es, tal vez, la más clara de todas (Mt 9,37s = Lc 10,2). En los profetas del Antiguo Testamento, y con mucha frecuencia en el Nuevo Testamento, esta imagen evoca la intervención definitiva de Dios al final de la historia para juzgar las acciones de los hombres (Mt 13,2470; Ap 14,15). La imagen de la pesca (Mc 1,17) tiene también connotaciones de juicio en el AT y en los escritos de Qumran (Jer 16,16; 1QH $3,26 ; 5,8)$. Y lo mismo puede decirse de la promesa de un pastor que Dios suscitará para guiar a su pueblo (Ez 34,23; 37,24), aunque esta imagen puede aplicarse mejor a Jesús que a los discípulos (Mt 9,36; Mc 6,34). Todas estas imágenes nos hablan de una misión urgente, que tiene como horizonte la intervención definitiva de Dios en la historia. Jesús anunció el inicio de dicha intervención cuando proclamaba: "ha comenzado a llegar el Reinado de Dios" (Mc 1,15). Las imágenes utilizadas para referirse a la misión son, por tanto, coherentes con el contenido central del mensaje de Jesús. No se trata de una tarea a largo plazo, para la que hace falta una organización estable, sino de una tarea urgente para la que apenas hay tiempo ${ }^{23}$.

Otro aspecto importante para entender cómo concebía Jesús esta misión es saber a quién iba dirigida. Al enviar a sus discípulos, Jesús no pensó en una misión de carácter universal, sino en hacer llegar a Israel la buena noticia de que las promesas de Dios se habían empezado a cumplir. El evangelio de Mateo es el que más claramente limita la misión prepascual a los confines de Israel (Mt 10,5-6.23), pero esta misma perspectiva está implícita en la importancia que tuvo el grupo de los Doce entre los discípulos de Jesús. Este grupo representaba germinalmente la restauración de Israel, y no es casual que en la tradición de Marcos los enviados de Jesús sean precisamente los Doce24.

23 Desde el punto de vista de las ciencias sociales el grupo de los discípulos de Jesús era una "facción", no un grupo estable. Una diferencia importante entre estos dos tipos de grupo es que la facción se reúne para una tarea concreta, que es externa al grupo y depende casi totalmente de la autoridad del líder que la forma. El grupo estable, sin embargo, tiene un objetivo interno, que se define por los intereses de sus miembros. Véase: B. J. Malina, The Social Gospel of Jesus. The Kingdom of God in Mediterranean Perspective (Minneapolis, Mn.: Fortress Press 2001) pp. 113-119.

${ }^{24}$ Los discípulos más cercanos de Jesús pudieron ser más de Doce, e incluso es posible que la identidad de los mismos variara con el tiempo, a medida que algunos se incorporaban al grupo y otros lo abandonaban. A pesar de ello, la institución de los Doce está 
Podemos decir, por tanto, que la misión encargada por Jesús a sus discípulos tuvo como primeros destinatarios a los miembros del pueblo de Israel. Pero a continuación hemos de precisar que dentro de Israel los destinatarios preferenciales de dicha misión fueron los sectores más marginados de la sociedad israelita, como indica el encargo de realizar exorcismos y curaciones, cuyos destinatarios eran, obviamente, quienes pertenecían a este estrato social. Esta forma de entender la misión suponía, en realidad, una ruptura de las fronteras sociales más arraigadas. En su contenido y en su forma, la misión encargada por Jesús a sus discípulos tenía un carácter inclusivo, que facilitó a los primeros cristianos la acogida de los no judíos en sus comunidades.

El elemento que da unidad a todos estos rasgos de la misión prepascual es su relación con la inminente llegada del Reinado de Dios. La urgencia de hacer llegar este mensaje con signos y palabras a todo Israel explicaría el hecho de que Jesús recurriera a la colaboración de los discípulos; también explicaría las imágenes utilizadas por él para hablar de la misión. Por otro lado, la naturaleza inclusiva de este Reinado explicaría el hecho de que los destinatarios preferenciales fueran los marginados. Todos estos elementos aparecen con nuevos matices en las diversas instrucciones para la misión que analizamos a continuación.

\section{El contenido del encargo misionero}

Una parte importante de estas instrucciones se refiere al contenido mismo de la misión, es decir, a aquello que Jesús encargó a sus discípulos. Lo más llamativo de esta parte de las instrucciones es el escaso lugar que ocupa la proclamación del mensaje. En contra de lo que pudiera parecer a primera vista, la acción prevalece sobre la palabra en el envío de los discípulos.

El encargo de proclamar la inminente llegada del Reinado de Dios se encuentra sólo en la tradición de Q, de donde lo toman Lucas y Mateo (Lc 10,9; Mt 10,7). Lo único que encontramos en el envío

muy arraigada en la tradición. Jesús quiso que sus discípulos más cercanos fueran doce, para simbolizar en ellos la renovación de las doce tribus de Israel. J. Gnilka, Die frühen Christen. Ursprünge und Anfang der Kirche (Freiburg: Herder 1999) pp. 181-183, ha subrayado recientemente la importancia del grupo de los Doce para entender la continuidad entre el grupo de los discípulos de Jesús y la Iglesia. 
misionero de Marcos, es una información del redactor sobre la actividad de los enviados, según la cual éstos predicaron la conversión (Mc 6,12), una expresión que en Marcos está relacionada con el anuncio de la llegada del Reinado de Dios (Mc 1,15). Sin embargo, las referencias más claras acerca del envío para anunciar un mensaje se encuentran en el marco narrativo que el evangelista ha puesto a las palabras de Jesús (Mc 6,12), lo mismo que la noticia del regreso de los enviados, en la que se dice que los discípulos se reunieron con Jesús y le contaron "lo que habían hecho y enseñado" (Mc 6,30). Estas dos noticias no cuadran con el núcleo más antiguo de las instrucciones para el envío (Mc 6,7-11), en las que nada se dice sobre dicho anuncio. Podemos concluir, por tanto, que el anuncio de un mensaje con palabras no fue el principal objetivo del envío misionero.

El principal encargo de Jesús a sus discípulos fue, más bien, anunciar un mensaje a través de acciones concretas. Tanto la tradición de Marcos como la de Q coinciden en esto, y señalan el exorcismo y la curación como el contenido básico de la misión. En Mc 6,7b se dice que Jesús dio a sus discípulos "autoridad sobre los espíritus inmundos". El evangelista comenta más tarde que "expulsaban a muchos demonios", y añade que "ungían con aceite a muchos enfermos y los curaban" (Mc 6,13). El redactor ha añadido el segundo elemento, lo mismo que Mateo y Lucas, tal vez por influjo de la tradición de Q, donde la curación sí ocupa un lugar central junto con el anuncio (Lc 10,9). Sin embargo, en el episodio del regreso de los Setenta y dos, vemos de nuevo que el elemento central es el exorcismo. Lo único que los discípulos le dicen a Jesús es: "Señor, incluso los demonios se nos someten en tu nombre" (Lc 10,17), a lo que él responde con un enigmático dicho, que tal vez refleja la experiencia vocacional que determinó su propia misión: "He visto a Satanás como un rayo cayendo del cielo" (Lc 10,18)25. Si como hemos afirmado más arriba estos dichos proceden de Q, entonces ambas tradiciones (Mc y Q) estarían de acuerdo en que el mandato de expulsar demonios fue el principal encargo de Jesús a sus discípulos.

25 Esta interpretación de Lc 10,18 ha sido propuesta por J. Marcus, "Jesus' Baptismal Vision" NTS 41 (1995) 512-521. La importancia de esta visión de la victoria sobre Satanás en la experiencia vocacional de Jesús, explicaría la relevancia que tuvieron los exorcismos en su actividad y en la misión que encomendó a sus discípulos. 
Esta conclusión es coherente con la importancia que los exorcismos tuvieron en la actuación de Jesús. La acusación de estar poseído y de expulsar los demonios con el poder de Belcebú aparece con frecuencia en los evangelios en tradiciones independientes (Mc 3,22.30; Jn 7,$20 ; 8,48-52 ; 10,20-21 ; 10,25)$, lo cual es un indicio de que esta actividad de Jesús fue importante. Jesús tuvo que defenderse de esta acusación, y explicar el sentido de su actividad como exorcista. El hecho de expulsar demonios es un signo de que ha comenzado la victoria sobre Satanás, y que el Reinado de Dios ha comenzado a llegar (Mt 9,32-34; 12,22-30; Mc 3,22-27; Lc 11,14-15.17-23)26. Este es también el sentido que tiene el encargo de expulsar demonios, porque en la cultura en que vivían Jesús y sus primeros discípulos este era el signo más elocuente de la actuación de Dios. Los exorcismos eran, por tanto, un mensaje en acto, un anuncio que realizaba lo que anunciaba, y por eso ocupan un lugar tan importante en la actuación de Jesús y en el envío misionero de los discípulos.

\section{La acogida y el rechazo de los misioneros}

Otro grupo de dichos recogidos en el llamado discurso de envío contiene instrucciones sobre cómo actuar en el camino, y sobre cómo comportarse ante la acogida y el rechazo. Este es, sorprendentemente, el aspecto en el que más coinciden la versión de Marcos y la de Q.

En las instrucciones para el camino (Mc 6,8-9 par.; Lc 10,4 par.) se pide a los misioneros que renuncien a los preparativos del viaje. Según Marcos, no han de llevar nada para el camino, ni pan, ni alforja, ni dinero; tan sólo un bastón para defenderse de las fieras o de los salteadores, unas sandalias y una sola túnica. Las instrucciones de Q son más escuetas: no llevar bolsa, ni alforja ni sandalias; pero añaden un dato interesante: no deben pararse a saludar a nadie por el camino. Estas recomendaciones tan detalladas reflejan el ethos de la misión, y el estilo de vida de los misioneros. El ethos de la misión viene deter-

${ }^{26}$ La estrecha relación entre exorcismo y misión que aparece en estos textos se comprende mejor cuando se sitúa en el marco de lo que significaba la posesión y el exorcismo en aquella cultura. Véase: Guijarro Oporto, S., "La dimensión política de los exorcismos de Jesús. La controversia de Belcebú desde la perspectiva de las ciencias sociales" Estudios Bíblicos 58 (2000) 51-77. 
minado por su urgencia. No hay tiempo que perder, y por eso no hay tiempo para largos preparativos, ni para los prolongados saludos orientales. Pero, al mismo tiempo, estas recomendaciones reflejan un estilo de vida que es característico de los discípulos de Jesús: no andar preocupados por las necesidades, pues el Padre se ocupa de ellos.

Las instrucciones sobre cómo reaccionar ante la acogida y el rechazo son las más extensas. En la versión de Marcos (Mc 6,10-11 par.) se consideran dos situaciones posibles: acogida o rechazo en un lugar (posiblemente un pueblo o una pequeña ciudad). Si los misioneros son bien acogidos, deben quedarse en la misma casa hasta que se vayan; pero si son rechazados, deben sacudirse el polvo de los pies como testimonio contra ese pueblo o ciudad.

La versión de Q es más detallada (Lc 10,5-12). En ella aparecen claramente diferenciados dos escenarios de la misión: la casa y la ciudad, que eran las dos instituciones básicas del mundo antiguo. Los misioneros han de llevar a las casas el mensaje de la paz, y allí donde sean acogidos han de practicar una comensalidad abierta, al estilo de Jesús. A esto se refiere la recomendación "comed lo que tengan" (Lc 10,7), es decir, comed sin deteneros a pensar si la comida cumple o no las leyes de la pureza ritual. Así lo entiende el Evangelio de Tomás, que relaciona esta invitación con otra palabra de Jesús sobre lo que mancha al hombre: "Si vais a cualquier tierra, y al marchar por los campos os reciben, comed lo que os pongan delante y sanad a los enfermos que haya entre ellos. No os manchará lo que entra en vuestra boca, sino lo que sale de vuestra boca, eso os manchará" (EvTom 14,3)27. Como en Marcos, se pide a los misioneros que no anden cambiando de casa. En caso de rechazo, la paz se volverá de nuevo sobre los misioneros.

A estas recomendaciones sobre la misión por las casas, siguen otras sobre la misión en las ciudades. En aquellas ciudades que acojan a los misioneros, la comensalidad abierta, que se menciona de nuevo en con la expresión "comed lo que os pongan" (Lc 10,8), ha de ir acompañada de curaciones y de un anuncio, que explicita el sentido de la comensalidad abierta y de las curaciones: está comenzando a llegar

27 Sobre la relación entre misión y comensalidad, véase: J. D. Crossan, The Historical Jesus. The Life of a Mediterranean Jewish Peasant (San Francisco: Harper 1991) pp. 333-344. El mismo Crossan ha profundizado en esta relación en una obra más reciente: Jesús: biografía revolucionaria (Barcelona: Grijalbo-Mondadori 1996) pp. 123-131. 
el Reinado de Dios. Cuando sean rechazados, lo mismo que en las recomendaciones de Marcos, los misioneros deben sacudirse el polvo de sus pies como testimonio contra aquellos pueblos o ciudades.

En este contexto podemos mencionar otra serie de dichos sobre el alcance de la acogida de los enviados (Mt 10,40; Lc 10,16; Jn 13,20). En todos ellos acoger a los misioneros equivale a acoger a Jesús. Es un aspecto que no aparece en las instrucciones sobre la misión, pero que refleja bien la mentalidad judía, según la cual el enviado representaba a todos los efectos a quien le enviaba.

Resulta muy difícil precisar cuál es el origen de cada una de estas instrucciones sobre la acogida y el rechazo de los misioneros. Es posible que algunos detalles se hayan subrayado más para responder a situaciones concretas de la misión durante la primera generación cristiana. Tal podría ser el caso de la insistencia en la comensalidad abierta en las instrucciones de Q y del EvTom, pues el tema de la comunión de mesa con los no judíos fue muy importante en ciertos ambientes cristianos durante la primera generación (Gál 2,11-14; Hch 15,1-35). Sin embargo, estas instrucciones reflejan en conjunto el contexto palestinense de la misión de Jesús. Gracias a ellas podemos acceder a la experiencia de los primeros enviados de Jesús: la acogida y el rechazo en las casas y en la ciudad, las formas concretas en que hacían presente el Reinado de Dios. Los misioneros de todas las épocas han podido reconocerse en estas experiencias, y por esta razón la Iglesia vuelve constantemente sobre ellas para seguir siendo fiel al mandato de su Señor.

\section{Conclusiones}

Llegados al final de este recorrido a través de los diversos textos sobre la misión de los discípulos en los evangelios, podemos recoger las principales conclusiones que han ido apareciendo a lo largo del mismo.

La presentación que los evangelios hacen de los textos sobre el envío de los discípulos antes y después de la resurrección de Jesús revela que esta forma de llevar a cabo la misión era para ellos un acontecimiento del pasado. En la segunda generación cristiana, que es la época en que se escribieron los evangelios, las preocupaciones de las comunidades estaban más centradas en su organización interna, y la forma de difundir el mensaje había cambiado. A pesar de ello, los redactores de 
los evangelios juzgaron que era importante conservar y transmitir con la mayor precisión posible las tradiciones que habían llegado hasta ellos sobre el envío de los discípulos. Esto significa que dicha tradición debía estar muy arraigada, porque conservaba un aspecto fundamental del movimiento de Jesús.

Esta conclusión se confirma cuando observamos que las tradiciones sobre el envío prepascual de los discípulos se encuentran atestiguadas de forma independiente en las fuentes más antiguas: el Documento Q, y el Evangelio de Marcos. En ambos escritos se encuentra una antigua colección de dichos de Jesús con recomendaciones para los misioneros. Es probable que esta instrucción se fuera formando a partir de dichos sueltos relacionados con la misión, semejantes a los que encontramos en otros lugares de estos mismos escritos. En todo caso, el hecho de que los recuerdos sobre el envío de los discípulos se hayan transmitido principalmente en los dichos de Jesús es un indicio más a favor de su antigüedad, aunque siempre debemos tener en cuenta que algunos de estos dichos pudieron haber sido modificados. Es posible también que a partir de estos dichos se crearan apotegmas, como en el caso del exorcista independiente de Mc 9,39-41, para responder a situaciones concretas de la misión en la primera generación cristiana.

A través del análisis diacrónico, que parte de la redacción de los evangelios, y rastrea la historia de las tradiciones a lo largo del periodo de la transmisión oral y escrita anterior a ellos, hemos podido llegar a un núcleo de tradiciones que con mucha probabilidad proceden de Jesús. En este núcleo pueden percibirse algunos de los rasgos característicos de la misión que encomendó a sus discípulos.

El primero de ellos es la novedad, y aparece reflejado en las imágenes con que se describe a los misioneros. Jesús no utiliza la terminología propia de los oficios religiosos, sino que se sirve de oficios comunes (pescador, jornalero y pastor) para referirse a ellos. Jesús no era un funcionario religioso, y tampoco quiso que sus enviados lo fueran. Su misión brota de una honda experiencia de Dios y de su proyecto, a cuyo servicio deben ponerse los enviados.

En segundo lugar, la misión encomendada por Jesús a sus discípulos se caracteriza por la urgencia. Las imágenes utilizadas para describirla (cosecha, pesca...) poseen connotaciones escatológicas y hacen referencia a una tarea urgente. Este dato indica que Jesús llamó a sus dis- 
cípulos para que le ayudaran en la tarea de anunciar la inminente llegada del Reinado de Dios, y no para crear un grupo que atendiera a las necesidades de sus miembros. Las instrucciones para el camino les exhortan a no perder el tiempo con largos saludos, ni tratando de convencer a quienes no reciban su anuncio.

En tercer lugar, hemos observado que esta misión tuvo unos destinatarios concretos. No fue un encargo general, sino concreto y urgente, que iba dirigido a los más cercanos. La constitución del grupo de los Doce y las referencias a una misión reservada a Israel apuntan en esta dirección. Sin embargo, no se trata de una misión excluyente, pues sus principales destinatarios fueron los marginados (enfermos, endemoniados, etc), e incluso algunos pagamos (centurión, mujer sirofenicia). Podemos decir que era una misión universal en lo concreto.

En cuarto lugar, la misión de los discípulos, como la de Jesús, no consistió principalmente en un anuncio con palabras, sino en un anuncio que se realizaba a través de la acción. Jesús encarga a sus enviados la tarea de realizar curaciones y exorcismos, y, sólo de forma secundaria, les manda explicar el sentido de lo que realizan proclamando que el Reinado de Dios está comenzando a llegar.

Finalmente, se trata de una misión realista, que conoce las dificultades con las que van a encontrarse los enviados. El rechazo es una posibilidad real, que ocupa un espacio considerable en las palabras de Jesús sobre la misión. Es posible que algunas de estas palabras sobre el rechazo hayan sido ampliadas a partir de la experiencia de los misioneros cristianos de la primera generación, pero con mucha probabilidad el núcleo de las mismas tiene su origen en la actividad de Jesús y sus primeros discípulos, que experimentaron el rechazo en numerosas ocasiones.

Me he detenido un poco en recordar y ordenar estos rasgos de la misión que Jesús encomendó a sus primeros discípulos, porque pueden ayudarnos a repensar la tarea misionera de nuestras comunidades, que es muy importante a la hora de planificar la pastoral vocacional. La llamada, entonces como ahora, está en función de la misión, y depende, por tanto, de la forma en que la entendamos y proyectemos. 